56 5 50

the

Porio vellide

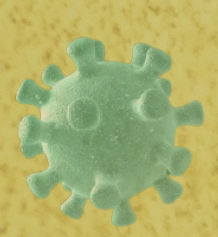

$t^{2}+4$

B R

AZIL (1)

\title{
ASPECTOS EPIDEMIOLÓGICOS
} DE DOENÇAS NO NORDESTE

\section{BRASILEIRO}

\section{Organizadores}

Maria Fernanda Barros Gouveia Diniz

Wallas Benevides Barbosa de Sousa

Maria Naiane Martins de Carvalho

Taís Gusmão da Silva

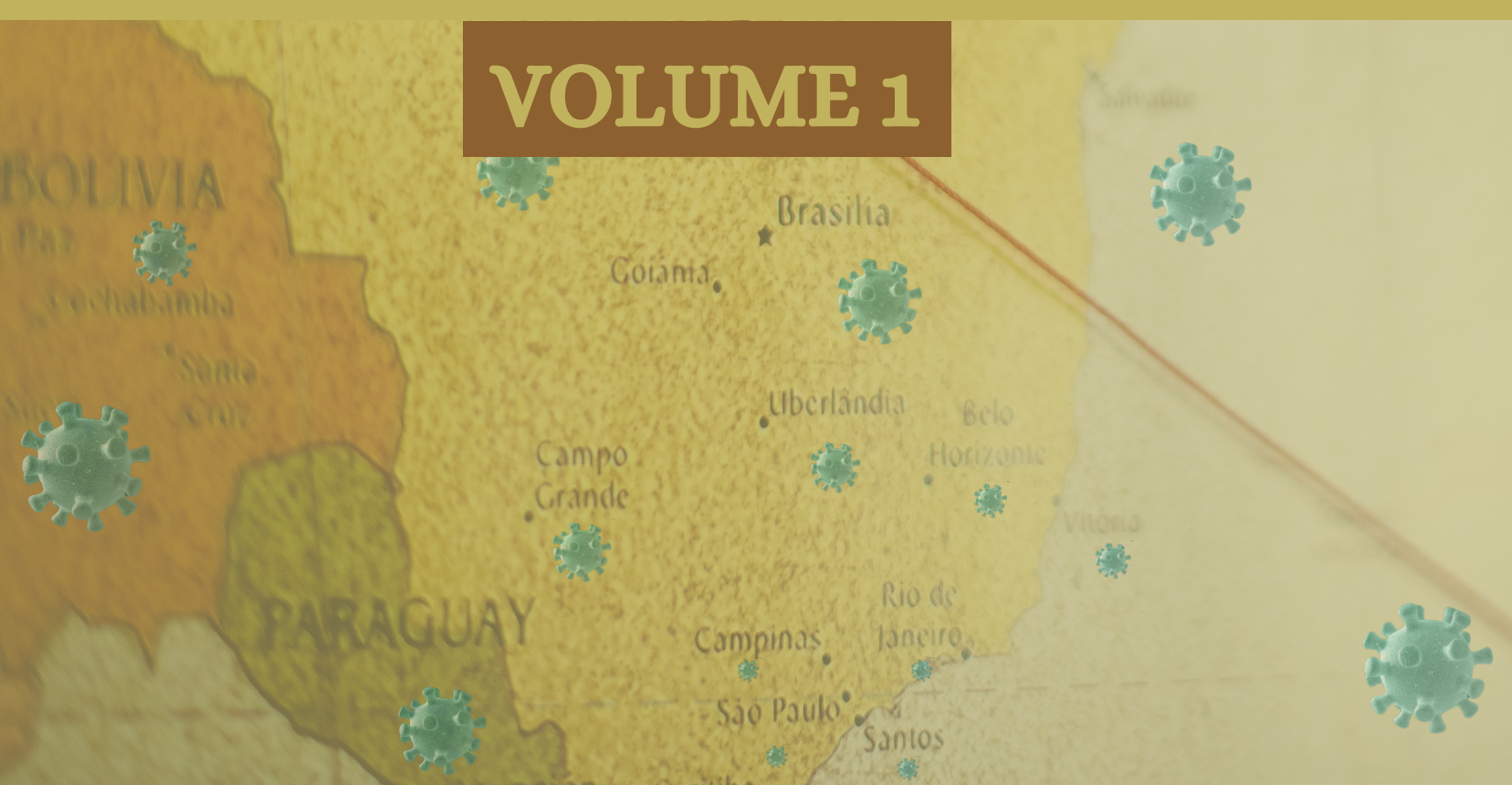



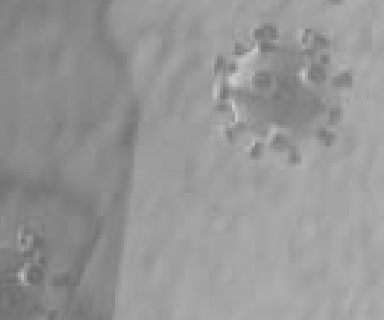

EDITORA

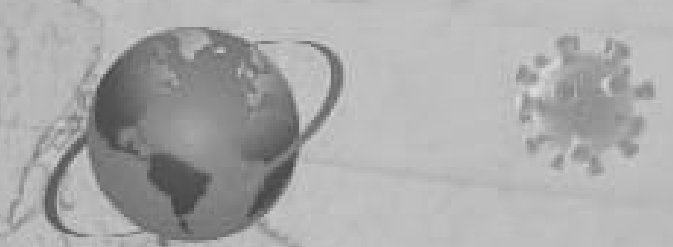

loric villin.

OMNIS SCIENTIA

慗

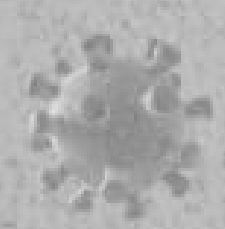

E. $^{2} \operatorname{lin}^{2}$

B B R

AZTL

\section{ASPECTOS EPIDEMIOLÓGICOS}

DE DOENÇAS NO NORDESTE

\section{BRASILEIRO}

Organizadores

Maria Fernanda Barros Gouveia Diniz

Wallas Benevides Barbosa de Sousa

Maria Naiane Martins de Carvalho

Taís Gusmão da Silva

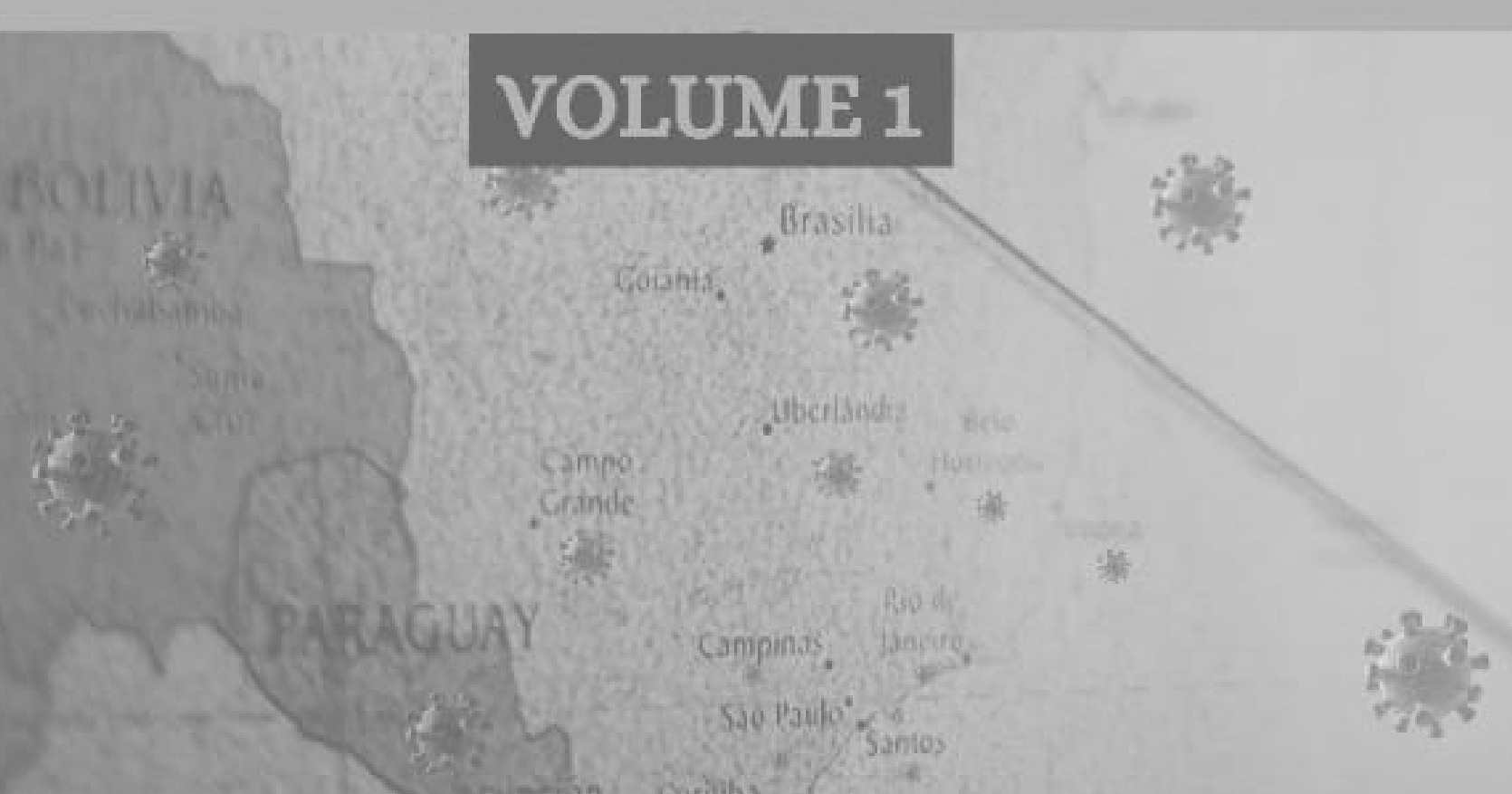


Editora Omnis Scientia

ASPECTOS EPIDEMIOLÓGICOS DE DOENÇAS NO NORDESTE BRASILEIRO

Volume 1

$1^{\mathrm{a}}$ Edição

TRIUNFO - PE

2022 


\section{Editor-Chefe}

Me. Daniel Luís Viana Cruz

\section{Organizadores}

Maria Fernanda Barros Gouveia Diniz

Wallas Benevides Barbosa de Sousa

Maria Naiane Martins de Carvalho

Taís Gusmão da Silva

\section{Conselho Editorial}

Dr. Cássio Brancaleone

Dr. Marcelo Luiz Bezerra da Silva

Dra. Pauliana Valéria Machado Galvão

Dr. Plínio Pereira Gomes Júnior

Dr. Walter Santos Evangelista Júnior

Dr. Wendel José Teles Pontes

Editores de Área - Ciências da Saúde

Dra. Camyla Rocha de Carvalho Guedine

Dra. Cristieli Sérgio de Menezes Oliveira

Dr. Leandro dos Santos

Dr. Hugo Barbosa do Nascimento

Dr. Marcio Luiz Lima Taga

Dra. Pauliana Valéria Machado Galvão

\section{Assistente Editorial}

Thialla Larangeira Amorim

\section{Imagem de Capa}

Freepik

\section{Edição de Arte}

Vileide Vitória Larangeira Amorim

\section{Revisão}

Os autores

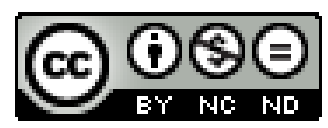

Este trabalho está licenciado com uma Licença Creative Commons - AtribuiçãoNãoComercial-SemDerivações 4.0 Internacional.

O conteúdo abordado nos artigos, seus dados em sua forma, correção e confiabilidade são de responsabilidade exclusiva dos autores. 
Dados Internacionais de Catalogação na Publicação (CIP) (eDOC BRASIL, Belo Horizonte/MG)

A838 Aspectos epidemiológicos de doenças no nordeste brasileiro [livro eletrônico] / Organizadoras Maria Fernanda Barros Gouveia Diniz... [et al.]. - Triunfo, PE: Omnis Scientia, 2022.

223 p. : il.

Formato: PDF

Requisitos de sistema: Adobe Acrobat Reader

Modo de acesso: World Wide Web

Inclui bibliografia

ISBN 978-65-88958-79-7

DOI 10.47094/978-65-88958-79-7

1. Epidemiologia. 2. Pandemia - Nordeste (Brasil). 3. Saúde pública. I. Diniz, Maria Fernanda Barros Gouveia. II. Sousa, Wallas Benevides Barbosa de. III. Carvalho, Maria Naiane Martins de. IV.Silva, Taís Gusmão da.

CDD 614.4

Elaborado por Maurício Amormino Júnior - CRB6/2422

Editora Omnis Scientia

Triunfo - Pernambuco - Brasil

Telefone: +55 (87) 99656-3565

editoraomnisscientia.com.br

contato@editoraomnisscientia.com.br 


\section{PREFÁCIO}

A obra intitulada: “ASPECTOS EPIDEMIOLÓGICOS DE DOENÇAS NO NORDESTE BRASILEIRO” traz informações epidemiológicas acerca da Pandemia provocada pela COVID-19, esquistossomose, arboviroses e diversos outros problemas de saúde pública, fornecendo assim dados para os órgãos de saúde e para a comunidade científica. Portanto, faz-se necessário compreender a epidemiologia para que sejam formuladas políticas de saúde, à organização do sistema de saúde e às intervenções destinadas para solucionar problemas específicos.

Espera-se que esta obra colabore com a produção científica a partir dos resultados obtidos nos estudos epidemiológicos, além de agregar o conhecimento científico, auxiliar no conhecimento dos profissionais, estudantes e sociedade e possibilitar o incentivo de estudos futuros para fortalecimento da pesquisa no Nordeste sobre o cenário atual de saúde, a partir de evidências científicas. 


\section{SUMÁRIO}

CAPÍTULO 1.

CENÁRIO EPIDEMIOLÓGICO DOS ÓBITOS POR CISTICERCOSE NO CEARÁ, NO PERÍODO DE 2010 A 2019

Wallas Benevides Barbosa de Sousa

Maria Fernanda Barros Gouveia Diniz

Maria Naiane Martins de Carvalho ${ }^{3}$

Bruno Melo de Alcântara

Maria Amanda Nobre Lisboa

José Anderson Soares da Silva

Arthur da Silva Nascimento

Dhenes Ferreira Antunes

Ana Joyce de Morais Bento

Maria Dandara Cidade Martins

Cicera Thainá Gonçalves da Silva

Mariana dos Santos Santana

DOI: 10.47094/978-65-88958-79-7/18-28

CAPÍtULO 2

PERFIL EPIDEMIOLÓGICO DA POPULAÇÃO NORDESTINA COM TÉTANO ACIDENTAL NO PERÍODO ENTRE 2016 E 2020

Maria Amanda Nobre Lisboa

Leonardo Vitor Alves da Silva

Bruno Melo de Alcântara ${ }^{3}$

Wallas Benevides Barbosa de Sousa

Maria Fernanda Barros Gouveia Diniz

Maria Naiane Martins de Carvalho

José Anderson Soares da Silva

Cicera Thainá Gonçalves da Silva

Arthur da Silva Nascimento 
Dhenes Ferreira Antunes

Tayslane dos Santos Gonçalves

Ana Joyce de Morais Bento

DOI: 10.47094/978-65-88958-79-7/29-38

CAPÍTULO 3

ESTUDO EPIDEMIOLÓGICO DOS CASOS DE ESCORPIONISMO NO ESTADO DO MARANHÃO DURANTE O ANO DE 2020

Wallas Benevides Barbosa de Sousa

Maria Fernanda Barros Gouveia Diniz

Maria Naiane Martins de Carvalho

Bruno Melo de Alcântara

Maria Amanda Nobre Lisboa

José Anderson Soares da Silva

Arthur da Silva Nascimento

Dhenes Ferreira Antunes

Shennovy Marrlon dos Santos

Maria Dandara Cidade Martins

Anayne Juca da Silva

DOI: 10.47094/978-65-88958-79-7/39-49

CAPÍTULO 4 .50

PERFIL EPIDEMIOLOGICO DA DISTRIBUIÇÃO DA TUBERCULOSE NO ESTADO DA BAHIA NO PERÍODO DE 2016 A 2020

Bruno Melo de Alcântara

Maria Amanda Nobre Lisboa

Wallas Benevides Barbosa de Sousa

Cicera Thainá Gonçalves da Silva

Clarice da Costa Sousa

Roniely Alencar Alves

Maria Fernanda Barros Gouveia Diniz 
José Anderson Soares da Silva

Arthur da Silva Nascimento

Dhenes Ferreira Antunes

Maria Naiane Martins de Carvalho

Maria Eduarda Xenofonte Carvalho

DOI: 10.47094/978-65-88958-79-7/50-59

CAPÍTULO 5

DENGUE NA REgiÃo METROPOLITANA DO CARIRI CEARENSE: ANÁliSE DO PERFIL EPIDEMIOLÓGICO

José Anderson Soares da Silva

Maria Naiane Martins de Carvalho

Maria Fernanda Barros Gouveia Diniz

Wallas Benevides Barbosa de Sousa

Bruno Melo de Alcântara

Maria Amanda Nobre Lisboa

Arthur da Silva Nascimento

Dhenes Ferreira Antunes

Elis Maria Gomes Santana

Gustavo Gomes Pinho

Thalyta Julyanne Silva de Oliveira

DOI: 10.47094/978-65-88958-79-7/60-66

CAPÍTULO 6.

ANÁLISE EPIDEMIOLÓGICA DOS CASOS DE LEISHMANIOSE VISCERAL NO ESTADO

DO MARANHÃO, NO PERÍODO DE 2015 A 2019

Ana Taynara Silva Lima

Cícero Pedro da Silva Junior

Roniely Alencar Alves

Maria Fernanda Barros Gouveia Diniz

Wallas Benevides Barbosa de Sousa 
Maria Naiane Martins de Carvalho

Elayne Eally Silva de Oliveira Morais

José Anderson Soares da Silva

Arthur da Silva Nascimento

Dhenes Ferreira Antunes

Maria Amanda Nobre Lisboa

Bruno Melo de Alcântara

DOI: 10.47094/978-65-88958-79-7/67-74

CAPÍTULO 7.

FEBRE CHIKUNGUNYA NO MUNICÍPIO DE CRATO, ESTADO DO CEARÁ: ASPECTOS EPIDEMIOLÓGICOS

Maria Naiane Martins de Carvalho

Maria Fernanda Barros Gouveia Diniz

Wallas Benevides Barbosa de Sousa

Sara Tavares de Sousa Machado

Maria Renata Furtado de Sousa

Cicera Ruth de Souza Machado

Cícero Damon Carvalho de Alencar

Bruno Melo de Alcântara

Maria Amanda Nobre Lisboa

José Anderson Soares da Silva

Dhenes Ferreira Antunes

Arthur da Silva Nascimento

DOI: 10.47094/978-65-88958-79-7/75-81

CAPÍTULO 8 .82

PERFIL CLÍNICO E EPIDEMIOLOGICO DA DISTRIBUIÇÃO DA SÍNDROME DA IMUNODEFICIÊNCIA ADQUIRIDA (AIDS) NO ESTADO DO MARANHÃO NO PERÍODO DE 2016 A 2020

Dhenes Ferreira Antunes

Maria Fernanda Barros Gouveia Diniz 
Wallas Benevides Barbosa de Sousa

Maria Naiane Martins de Carvalho

Maria Dandara Cidade Martins

Ana Lyvia Secundo Sampaio

Arthur da Silva Nascimento

Bruno Melo de Alcântara

Maria Amanda Nobre Lisboa

José Anderson Soares da Silva

Tayslane dos Santos Gonçalves

Adeilson Calixto de Sousa

DOI: 10.47094/978-65-88958-79-7/82-93

CAPÍTULO 9 .94

ZOONOSES CAUSADAS POR PROTOZOÁRIOS NO ESTADO DE PERNAMBUCO: UMA ANÁLISE EPIDEMIOLÓGICA

Maria Naiane Martins de Carvalho

Maria Fernanda Barros Gouveia Diniz

Wallas Benevides Barbosa de Sousa

Taís Gusmão da Silva

Sara Tavares de Sousa Machado

Bruno Melo de Alcântara

Maria Amanda Nobre Lisboa

José Anderson Soares da Silva

Arthur da Silva Nascimento

Dhenes Ferreira Antunes

Maria Eduarda Xenofonte Carvalho

DOI: 10.47094/978-65-88958-79-7/94-105 
COVID-19 EM NÚMEROS: IMPACTOS DA PANDEMIA EM PROFISSIONAIS DE SAÚDE

Cícero Damon Carvalho de Alencar

Antonio Rony da Silva Pereira Rodrigues

Danielle de Oliveira Brito Cabral

Maria Lucilândia de Sousa

Maria Naiane Martins de Carvalho

Maria Fernanda Barros Gouveia Diniz

Wallas Benevides Barbosa de Sousa

Arthur da Silva Nascimento

Bruno Melo de Alcântara

Maria Amanda Nobre Lisboa

Dhenes Ferreira Antunes

José Anderson Soares da Silva

DOI: 10.47094/978-65-88958-79-7/106-115

CAPÍTULO 11

ANÁliSE EPIDEMIOLÓGICA DOS CASOS DE MENINGITE NO NORDESTE BRASILEIRO, NO PERÍODO DE 2016 A 2020

Taís Gusmão da Silva

Maria Naiane Martins de Carvalho

Maria Renata Furtado de Sousa

Gabriel Venancio Cruz

Cícero Damon Carvalho de Alencar

Arthur da Silva Nascimento

Maria Amanda Nobre Lisboa

Bruno Melo de Alcântara

José Anderson Soares da Silva

Dhenes Ferreira Antunes

Maria Fernanda Barros Gouveia Diniz

Wallas Benevides Barbosa de Sousa 
CAPÍTULO 12

EPIDEMIOLOGIA DA DOENÇA DE CHAGAS AGUDA NO ESTADO DO MARANHÃO ENTRE 2011 A 2019

Wallas Benevides Barbosa de Sousa

Maria Fernanda Barros Gouveia Diniz

Maria Naiane Martins de Carvalho

Bruno Melo de Alcântara

Maria Amanda Nobre Lisboa

José Anderson Soares da Silva

Arthur da Silva Nascimento

Dhenes Ferreira Antunes

Ana Joyce de Morais Bento

Renata Alves Fernandes

Cicera Thainá Gonçalves da Silva

Clarice da Costa Sousa

DOI: 10.47094/978-65-88958-79-7/126-136

CAPÍTULO 13

PERFIL EPIDEMIOLÓGICO DE ZIKA VÍRUS NA CIDADE DE FORTALEZA, NO PERÍODO DE 2016 A 2020

Maria Fernanda Barros Gouveia Diniz

Wallas Benevides Barbosa de Sousa

Maria Naiane Martins de Carvalho

Bruno Melo de Alcântara

Maria Amanda Nobre Lisboa

Arthur da Silva Nascimento

José Anderson Soares da Silva

Dhenes Ferreira Antunes

Maria Elenilda Paulino da Silva 
Larisse Bernardino dos Santos

Francisco Fernando Ferreira Garcia

DOI: 10.47094/978-65-88958-79-7/137-146

CAPÍTULO 14. 147

ESTUDO EPIDEMIOLÓGICO DOS CASOS DE ACIDENTES COM ARANHAS DE IMPORTÂNCIA EM SAÚDE PÚBLICA NO ESTADO DO PERNAMBUCO DURANTE OS ANOS DE 2016 A 2020

Wallas Benevides Barbosa de Sousa

Maria Fernanda Barros Gouveia Diniz

Maria Naiane Martins de Carvalho

Bruno Melo de Alcântara

Maria Amanda Nobre Lisboa

Arthur da Silva Nascimento

José Anderson Soares da Silva

Dhenes Ferreira Antunes

Shennovy Marrlon dos Santos

Maria Dandara Cidade Martins

Elis Maria Gomes Santana

Gustavo Gomes Pinho

DOI: 10.47094/978-65-88958-79-7/147-158

CAPÍTULO 15 159

ESTUDO EPIDEMIOLÓGICO DA MALÁRIA DE CASOS NO ESTADO DA BAHIA, NO PERÍODO DE 2016 A 2020

Cícero Pedro da Silva Junior

Ana Taynara Silva Lima

Arthur da Silva Nascimento

Ana Joyce de Morais Bento

Maria Fernanda Barros Gouveia Diniz

Wallas Benevides Barbosa de Sousa

Maria Naiane Martins de Carvalho 
Bruno Melo de Alcântara

Maria Amanda Nobre Lisboa

José Anderson Soares da Silva

Dhenes Ferreira Antunes

Tayslane dos Santos Gonçalves

DOI: 10.47094/978-65-88958-79-7/159-166

CAPÍTULO 16

ASPECTOS EPIDEMIOLÓGICOS DOS ACIDENTES POR ANIMAIS PEÇONHENTOS NO PERÍODO DE 2015 A 2019, NO ESTADO DO CEARÁ

Maria Naiane Martins de Carvalho

Wallas Benevides Barbosa de Sousa

Maria Fernanda Barros Gouveia Diniz

Luís Pereira de Morais

Mayara Maria da Silva

Bruno Melo de Alcântara

Maria Amanda Nobre Lisboa

José Anderson Soares da Silva

Arthur da Silva Nascimento

Dhenes Ferreira Antunes

Cícero Damon Carvalho de Alencar

Maria Renata Furtado de Sousa

DOI: 10.47094/978-65-88958-79-7/167-179

CAPÍTULO 17 180

SITUAÇÃO EPIDEMIOLÓGICA DA LEPTOSPIROSE NO ESTADO DO CEARÁ, NO PERÍODO DE 2014 A 2019

Maria Fernanda Barros Gouveia Diniz

Wallas Benevides Barbosa de Sousa

Maria Naiane Martins de Carvalho

Bruno Melo de Alcântara 
Maria Amanda Nobre Lisboa

Arthur da Silva Nascimento

José Anderson Soares da Silva

Dhenes Ferreira Antunes

Lucas Yure Santos da Silva

Nayra Thaislene Pereira Gomes

José Iago Muniz

DOI: 10.47094/978-65-88958-79-7/180-190

CAPÍTULO 18

PERFIL EPIDEMIOLÓGICO DA LEISHMANIOSE TEGUMENTAR NA BAHIA NO PERÍODO DE 2015 A 2019

Cicera Thainá Gonçalves da Silva

Bruno Melo de Alcântara

Clarice da Costa Sousa

Wallas Benevides Barbosa de Sousa

Maria Fernanda Barros Gouveia Diniz

Maria Naiane Martins de Carvalho

Maria Amanda Nobre Lisboa

Arthur da Silva Nascimento

José Anderson Soares da Silva

Dhenes Ferreira Antunes

Tayslane dos Santos Gonçalves

Adeilson Calixto de Sousa

DOI: 10.47094/978-65-88958-79-7/191-200

CAPÍTULO 19

ASPECTOS EPIDEMIOLÓGICO DOS CASOS DE HEPATITE B NO ESTADO DA BAHIA DURANTE OS ANOS DE 2014 A 2018

Maria Fernanda Barros Gouveia Diniz

Wallas Benevides Barbosa de Sousa 
Maria Naiane Martins de Carvalho

Bruno Melo de Alcântara

Maria Amanda Nobre Lisboa

Arthur da Silva Nascimento

José Anderson Soares da Silva

Dhenes Ferreira Antunes

Ana Lyvia Secundo Sampaio

Larissa da Silva

Cicera Laura Roque Paulo

DOI: 10.47094/978-65-88958-79-7/201-211

CAPÍTULO 20

ANÁLISE DA SITUAÇÃO EPIDEMIOLÓGICA DA ESQUISTOSSOMOSE NO ESTADO DE

PERNAMBUCO, BRASIL

José Anderson Soares da Silva

Maria Naiane Martins de Carvalho

Maria Fernanda Barros Gouveia Diniz

Wallas Benevides Barbosa de Sousa

Bruno Melo de Alcântara

Maria Amanda Nobre Lisboa

Arthur da Silva Nascimento

Dhenes Ferreira Antunes

Ana Joyce de Morais Bento

Vinicius Pereira Dias

Vanessa Pereira Dias

Cicera Alane Coelho Gonçalves

DOI: 10.47094/978-65-88958-79-7/212-219 


\section{Maria Fernanda Barros Gouveia Diniz';}

Universidade Regional do Cariri (URCA), Crato, Ceará.

http://lattes.cnpq.br/4011999062877801

Wallas Benevides Barbosa de Sousa²;

Universidade Regional do Cariri (URCA), Crato, Ceará.

http://lattes.cnpq.br/2728094302439807

Maria Naiane Martins de Carvalho ${ }^{3}$;

Universidade Regional do Cariri (URCA), Crato, Ceará.

http://lattes.cnpq.br/1367905326694768

\section{Bruno Melo de Alcântara ${ }^{4}$;}

Universidade Regional do Cariri (URCA), Crato, Ceará.

http://lattes.cnpq.br/8604223319950019

Maria Amanda Nobre Lisboa ${ }^{5}$;

Universidade Regional do Cariri (URCA), Crato, Ceará.

http://lattes.cnpq.br/9262877018230108

Arthur da Silva Nascimento ${ }^{6}$;

Universidade Regional do Cariri (URCA), Crato, Ceará.

http://lattes.cnpq.br/2889559933133277

José Anderson Soares da Silva ${ }^{7}$;

Universidade Regional do Cariri (URCA), Crato, Ceará.

http://lattes.cnpq.br/5906691562269815

\section{Dhenes Ferreira Antunes;}

Universidade Regional do Cariri (URCA), Crato, Ceará.

http://lattes.cnpq.br/3922373252537278

\section{Lucas Yure Santos da Silva';}

Universidade Regional do Cariri (URCA), Crato, Ceará.

http://lattes.cnpq.br/9971771944171553 


\section{Nayra Thaislene Pereira Gomes ${ }^{10}$;}

Universidade Regional do Cariri (URCA), Crato, Ceará.

http://lattes.cnpq.br/4215597540387398

\section{José Iago Muniz"11.}

Universidade Regional do Cariri (URCA), Crato, Ceará.

http://lattes.cnpq.br/0756453532947473

RESUMO: Leptospirose é uma zoonose com distribuição mundial, que acomete animais domésticos, silvestres e o homem. O agente etiológico são bactérias do gênero Leptospira, microrganismos capazes de se disseminar nos tecidos, e causar doenças crônicas em um grande número de animais selvagens e domésticos. O presente estudo teve como objetivo realizar um levantamento epidemiológico acerca da Leptospirose no Estado do Ceará, no período de 2014 a 2019. Trata-se de um estudo epidemiológico, quantitativo-descritivo, retrospectivo, desenvolvido a partir de dados secundários dispostos pelo Sistema de Informação de Agravos de Notificação (SINAN). As variáveis epidemiológicas analisadas foram o ano de notificação, sexo, zona de residência, critério de confirmação e evolução clínica dos acometidos. De acordo com os dados obtidos a partir do SINAN, um total de 312 casos de Leptospirose foram notificados no período de 2014 a 2019 no Ceará. A distribuição de casos notificados por ano se deu da seguinte maneira: 50 casos em 2014, 29 em 2015, 49 em 2016, 28 em 2017, 51 em 2018 e 105 em 2019. Os indivíduos mais acometidos foram do sexo masculino com 77,24\% dos casos, apresentando maior propensão de ser acometido pela doença em função desse sexo está mais exposto a situações ou práticas que facilitem o contato com o agente etiológico. Com relação à faixa etária $39,42 \%$ dos casos ocorreram em pessoas com idade entre 20 e 49 anos. A leptospirose é uma zoonose de grande importância para saúde pública, assim os resultados obtidos no presente estudo têm suma importância para a vigilância epidemiológica, além de servir como alicerce nas intensificações dos meios de prevenção, combate e controle da leptospirose no Ceará.

PALAVRAS-CHAVE: Bactéria. Leptospira. Urina de animais.

\section{EPIDEMIOLOGICAL SITUATION OF LEPTOSPIROSIS IN THE STATE OF CEARÁ, FROM 2014 TO 2019}

ABSTRACT: Leptospirosis is a zoonosis with worldwide distribution, which affects domestic animals, wild animals and humans. The etiologic agent is bacteria of the Leptospira genus, microorganisms capable of spreading to tissues and causing chronic diseases in a large number of wild and domestic animals. This study aimed to conduct an epidemiological survey about Leptospirosis in the State of Ceará, from 2014 to 2019. This is an epidemiological, quantitative-descriptive, retrospective study, developed from secondary data provided by the Information System of Notification of Appeals (SINAN). The epidemiological variables analyzed were the year of notification, gender, area of 
residence, confirmation criteria and clinical evolution of the affected individuals. According to data obtained from SINAN, a total number of 312 cases of Leptospirosis were reported from 2014 to 2019 in Ceará. The distribution of reported cases per year was as follows: 50 cases in 2014, 29 in 2015, 49 in 2016, 28 in 2017, 51 in 2018 and 105 in 2019. The most affected individuals were males, with $77.24 \%$ of the cases, showing a greater propensity to be affected by the disease as result of this gender being more exposed to situations or practices that facilitate contact with the etiological agent. With regard to age group, 39.42\% of cases occurred in people aged between 20 and 49 years. Leptospirosis is a zoonosis of great importance for public health, so the results obtained in this study are of paramount importance for epidemiological surveillance, in addition to serving as a foundation in the escalation of means of prevention, combat and control of leptospirosis in Ceará.

KEY-WORDS: Bacterium. Leptospira. Animal urine.

\section{INTRODUÇÃO}

A Leptospirose é uma doença zoonótica de ampla distribuição mundial, é causada por bactérias do gênero Leptospira, família Leptospiraceae, ordem Spirochaeles (FIGUEIRA, 2011; GREENE, 2015). A principal espécie relacionada a essa enfermidade, é a Leptospira interrogans (Stimson, 1907) Wenyon, 1926, devido seu alto poder patogênico (SALOMÃO, 2017).

De acordo com Burr et al. (2009) e Marinho \& Tavares (2015) a maior parte das infecções humanas ocorrem por contato com urina infectada, principalmente de ratos, água ou solo contaminados pela urina, tecidos de animais infectados, ingestão de água ou alimentos contaminados, mordeduras e fômites.

Os ratos são considerados o principal animal reservatório e disseminador da Leptospirose em meio urbano, podendo durante toda a sua vida, eliminar cepas patogênicas através da urina para o meio ambiente, não excluindo o fato que outros animais também podem disseminar esse patógeno, como os cães, que possuem uma alta suscetibilidade a essas bactérias, o que é muito preocupante, já que os mesmos apresentam uma grande proximidade com os humanos (PARREIRA, 2009; FERNANDES, et al, 2013; GREENE, 2015; MARINHO \& TAVARES, 2015).

No estado do Ceará, de 1985 a 2004 foram registrados mais de dois mil casos de Leptospirose, evidenciando a persistência e tendência de crescimento dessa doença, principalmente em áreas urbanas (CEARÁ, 2005). A transmissão dessa zoonose frequentemente está associada a existência de condições favoráveis para sobrevivência da Leptospira no meio, a disponibilidade e quantidade de animais susceptíveis ou portadores na população e do nível de contato entre esses animais com o homem (LEVETT, 2004).

Exposições a enchentes, alagamentos, manejo de animais e moradias em condições insalubres, são alguns dos principais fatores que propiciam contágio da Leptospirose (BRASIL, 2014).

Diversos fatores podem influenciar no diagnóstico da Leptospirose, como a fase em que a doença se expõe, a quantidade de testes disponíveis para o diagnóstico e a abundância de diagnósticos diferencias (MARINHO; TAVARES, 2015). Considerando esses fatores, é de suma importância uma 
descrição detalhada da anamnese, sempre pesquisar o histórico médico do paciente, a realização de exames clínicos e laboratoriais, e também a verificação de análises epidemiológicas (MARTIN et al., 2019).

Entres os testes laboratoriais existentes, o ELISA e a Microaglutinação (MAT) são os exames de rotina mais utilizados, com suma importância para determinar o diagnóstico (BRASIL, 2014). Porém, é recomendado que caso de suspeita de Leptospirose, é preconizado iniciar o uso de uma antibioticoterapia imediatamente, mesmo antes de sair o resultado do exame sorológico (LARA et al., 2019).

Segundo Rodrigues (2008), para a prevenção da Leptospirose, é necessário a implantação de diversas medidas de controle, tais como: Controle da população de roedores, manutenção de ambientes favoráveis a sobrevivência dessas bactérias, isolamento e tratamento dos animais infectados, além de evitar o contato com água da enchente. Também é importante que a população do local seja bem informada sobre a epidemiologia da Leptospirose e da importância de sua prevenção, por meio de medidas sanitárias no ambiente e nos animais domésticos (JORGE et al. 2011).

No Brasil, a Leptospirose apresenta um padrão de distribuição endêmico, além de poder ocorrer em todos os meses do ano, principalmente em localidades carentes, com pós-enchentes, inundações e surtos (FLORES et al., 2020). O presente estudo tem como objetivo identificar os aspectos epidemiológicos da Leptospirose no estado do Ceará, no período de 2014 a 2019. Com isso, a Leptospirose é avaliada como um problema de saúde pública com altos taxas de prevalência, sendo assim, de suma importância socioeconômica. Portanto, o conhecimento científico se faz necessário para expor dados desta enfermidade, como sua taxa incidência durante os anos no estado do Ceará, para que seja feito um aprimoramento nas ações de controle de doenças com o intuito de amenizar o número de casos.

\section{METODOLOGIA}

Trata-se de um estudo de caráter epidemiológico descritivo/quantitativo, retrospectivo, de corte transversal, sobre os casos notificados de Leptospirose, que foi realizado utilizando dados secundários de domínio público dispostos pelo Sistema de Informação de Agravos Nacional (SINAN), disponibilizado no Departamento de Informática do Sistema único de Saúde (DATASUS).

Foram avaliados casos notificados de Leptospirose no estado do Ceará, no período de 2014 a 2019. Para determinar o perfil epidemiológico da enfermidade, os dados foram coletados seguindo as variáveis: Ano de notificação, sexo, zona de residência, critério de confirmação e evolução clínica dos acometidos.

Os casos suspeitos têm como sintomatologia febre, cefaleia, mialgia associadas à pelo menos um quadro clínico, seja o ampliamento da bilirrubina, a icterícia, insuficiência renal ou exposição a inundações, água ou terreno barroso nos 30 dias que antecede o início dos sintomas e sinais. Já os casos com confirmação são caracterizados pelas mesmas sintomatologias mais a constatação de resultados de exames laboratoriais específicos com reagente para a Leptospira (GOVERNO DO 
ESTADO DA BAHIA, 2017).

A região do Nordeste Brasileiro, tem uma ampla variação de chuva tanto anual quanto intrasazonal, devido a influência da temperatura dos oceanos Pacífico e Atlântico que fazem o controle e a variação de secas e enchentes da região (ALVES et al., 2017; LYRA et al., 2017). Como está região é de clima semiárido, as ocorrências de Leptospirose estão relacionadas as altas concentrações de animais em localidades próximas a águas estagnadas (OLIVEIRA et al., 2013; SILVA et al., 2018).

A análise dos dados obtidos foi realizada por meio de métodos estatísticos de percentual através do programa Microsoft Excel 2019, sendo amostrada em forma de gráfico e tabela.

Devido ao fato de o presente estudo utilizar dados de domínio público, de livre acesso pelo departamento do DATASUS, não foi necessário submetê-lo ao Comitê de Ética em Pesquisa (CEP) da Comissão Nacional de Ética em Pesquisa (CONEP), pois as pesquisas foram realizadas usando dados secundários sem o envolvimento de seres humanos.

\section{RESULTADOS E DISCUSSÕES}

No período de 2014 a 2019, foram notificados 312 casos confirmados de leptospirose no Estado do Ceará, com média anual de 52 casos. Na amostra, constatou-se que houve um aumento no número de casos em relação aos períodos avaliados, com exceção dos anos de 2015 e 2017, no qual obtiveram uma queda significativa, já o ano de 2019, apresentou o maior número de casos notificados. (Figura 1).

Figura 1: Distribuição de casos de leptospirose por ano no Estado do Ceará, entre 2014 a 2019.

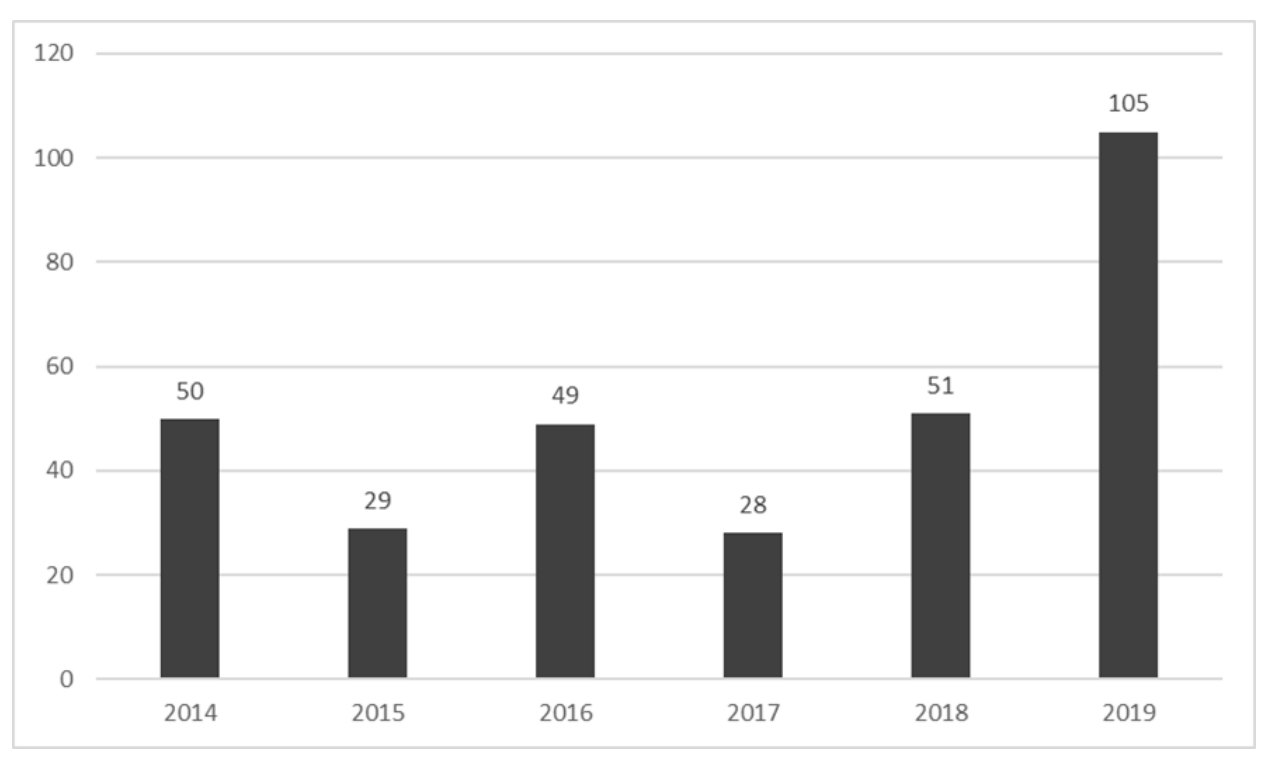

Fonte: Dados da Pesquisa (2021).

Mais da metade dos casos notificados pelo SINAN, mais especificamente 77,24\%, foram registrados como sendo do sexo masculino (Tabela 1), além disso a maioria dos casos ocorreram em indivíduos com idade entre 20-39 anos e 40-59 anos, para ambos os sexos (Figura 2). Realidade 
também encontrada nos estudos de Basso e Righi (2015) em Porto Alegre, estado do Rio Grande do Sul, Oliveira et al. (2016) na baixada fluminense, estado do Rio de Janeiro, Baracho et al., (2017) no estado de Pernambuco e Rodrigues (2019) no estado do Acre. Em todo o Brasil os homens são os mais afetados, principalmente com idade entre 20 a 49 anos, sendo esses os mais expostos a doença pela pratica de atividade que esteja em contato com a fonte da infecção, como coleta de lixo urbano, limpeza de bueiros, instalação e manutenção de rede de esgoto, controle de roedores, entre outras atividades de risco, havendo uma média de mais de 350 mortes por ano, de homens por infecções de leptospirose (BUZZAR, 2011; BRASIL, 2018; BRASIL, 2019).

Tabela 1: Distribuição de casos de leptospirose por sexo no Estado do Ceará, entre 2014 a 2019.

\begin{tabular}{|c|c|c|c|c|c|c|c|c|}
\hline \multirow{2}{*}{ Variável } & \multicolumn{6}{|c|}{ Ano } & \multirow{2}{*}{ Total } & \multirow{2}{*}{$(\%)$} \\
\hline & 2014 & 2015 & 2016 & 2017 & 2018 & 2019 & & \\
\hline \multicolumn{9}{|l|}{ Sexo } \\
\hline Masculino & 38 & 23 & 41 & 25 & 34 & 80 & 241 & $77,24 \%$ \\
\hline Feminino & 12 & 6 & 8 & 3 & 17 & 25 & 71 & $22,76 \%$ \\
\hline
\end{tabular}

Fonte: Dados da Pesquisa (2021).

Figura 2: Distribuição de casos de leptospirose por sexo e faixa etária no Estado do Ceará, entre 2014 a 2019.

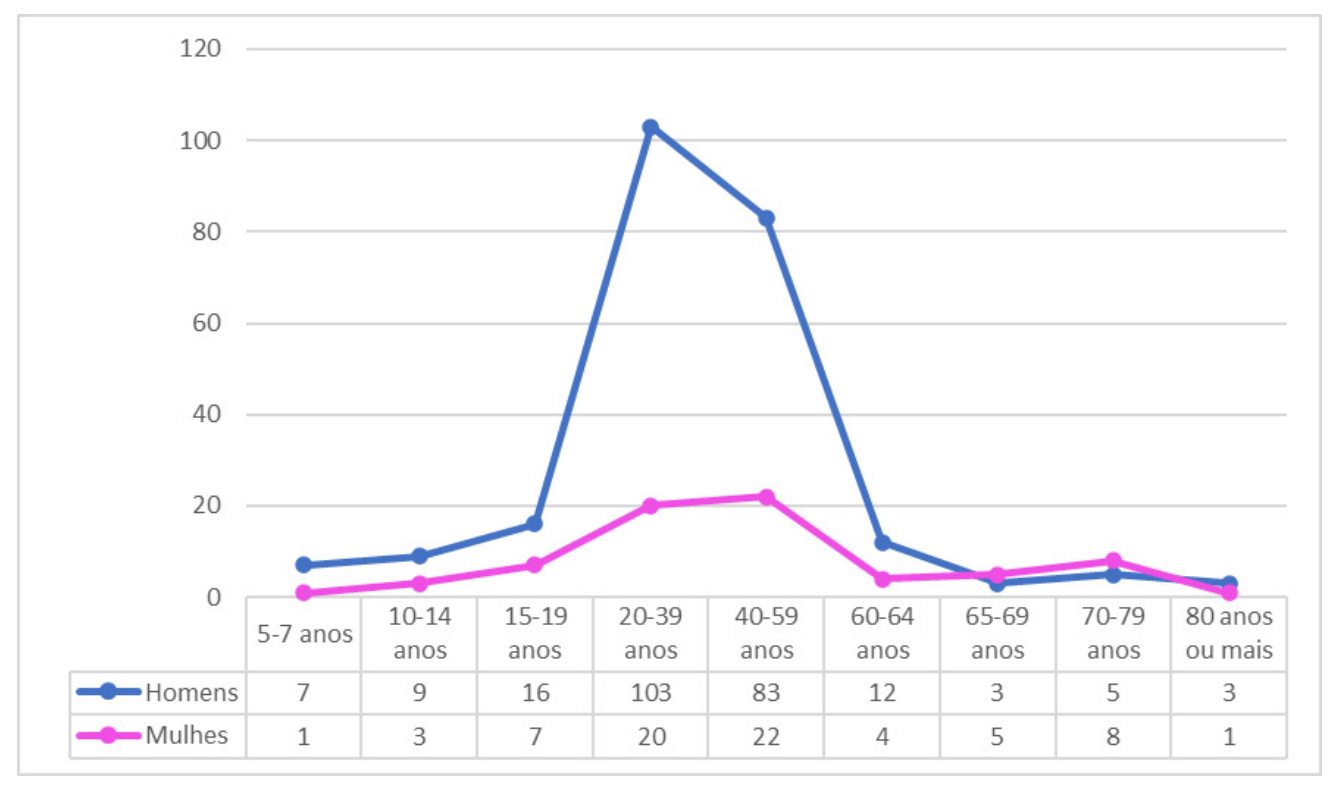

Fonte: Dados da Pesquisa (2021).

Por todo o período analisado, a maior parte das infecções ocorreram em residentes de áreas urbanas (Tabela 2). Resultados consoantes com os encontrados em Sampaio et al. (2011), Souza et al. (2011), Pereira et al. (2014) e Rodrigues (2019), em que a ocorrência da leptospirose é de predominância na zona urbana. Essa maior incidência em arias urbana deve-se, provavelmente, 
por causa da aglomeração populacional de baixa renda, vivendo próximo de córregos, com baixa infraestrutura sanitária e falta de saneamento básico adequado, que são fatores que predispõe a infestações dos roedores, e a crescente impermeabilização do solo, além da urbanização acelerada, que possibilita a fuga dos roedores do campo para a cidade, aumentando assim o número de reservatório para a persistência de focos de infecção (ANA, 2002; FONSECA et al., 2011; CLAZER et al., 2015). Apesar da leptospirose é caracterizada como uma doença endêmica, mas quando se tem grandes picos de precipitações, ela pode torna-se epidêmica, principalmente em áreas urbanas, devido a enchentes e alagamentos associadas a grande quantidade populacional nestas localidades (CHAIBLICH et al., 2017).

Tabela 2: Distribuição de casos de leptospirose por zona de residência no Estado do Ceará, entre 2014 a 2019.

\begin{tabular}{ccccccccc}
\hline \multirow{2}{*}{ Variável } & \multicolumn{9}{c}{ Ano } & Total & (\%) \\
\cline { 2 - 5 } & $\mathbf{2 0 1 4}$ & $\mathbf{2 0 1 5}$ & $\mathbf{2 0 1 6}$ & $\mathbf{2 0 1 7}$ & $\mathbf{2 0 1 8}$ & $\mathbf{2 0 1 9}$ & \\
\hline Zona de residência & & & & & & & & \\
Urbana & 35 & 23 & 40 & 24 & 42 & 93 & 257 & $82,37 \%$ \\
Rural & 12 & 5 & 4 & 2 & 7 & 9 & 40 & $12,82 \%$ \\
Periurbana & 1 & - & - & - & - & 2 & 3 & $0,96 \%$ \\
Ign/Branco & 1 & 1 & 5 & 2 & 2 & 1 & 12 & $3,85 \%$ \\
\hline
\end{tabular}

Fonte: Dados da Pesquisa (2021).

Foi possível notar que a maioria dos casos foram confirmado por exames clínico-laboratorial (Tabela 3), reforçando a importância destes testes. O reconhecimento das características clínicas e dos dados epidemiológicos da leptospirose são fundamentais, porém a exibição inespecífica, sendo necessária exames clínicos, uma vez que a leptospirose é diversas vezes diagnosticada inapropriadamente, devido a vasta quantidade de diagnósticos diferenciais e ausência de testes laboratoriais adequados (BRASIL, 2020). O método de referência para a detecção da infecção de leptospirose em homens e animais, é a reação soroaglutinação microscópica, que é capaz de detectar IgM e IgG, permitindo até identificação do sorogrupo infectante (TEIXEIRA. et al.,2008; ADLER \& MOCTEZUMA, 2010; LEMOS et al., 2010). Os testes de diagnóstico rápido para leptospirose vêm melhorando a cada ano, porém, como há a possibilidade de que se tenha um falso negativo, o tratamento empírico deve ser iniciado imediatamente caso suspeite-se infecção (HAAKE \& LEVETT, 2015). 
Figura 3: Distribuição de casos de leptospirose por critério de confirmação da doença no Estado do Ceará, entre 2014 a 2019.

\begin{tabular}{ccccccccc}
\hline Variável & \multicolumn{9}{c}{ Ano } & Total & (\%) \\
\cline { 2 - 6 } & $\mathbf{2 0 1 4}$ & $\mathbf{2 0 1 5}$ & $\mathbf{2 0 1 6}$ & $\mathbf{2 0 1 7}$ & $\mathbf{2 0 1 8}$ & $\mathbf{2 0 1 9}$ & & \\
\hline Critério de confirmação & & & & & & & & \\
Clínico-Laboratorial & 47 & 26 & 41 & 22 & 44 & 93 & 273 & $87,50 \%$ \\
Clínico-epidemiológico & 2 & 3 & 8 & 5 & 3 & 11 & 32 & $10,26 \%$ \\
Ign/Branco & 1 & - & - & 1 & 4 & 1 & 7 & $2,24 \%$ \\
\hline
\end{tabular}

Fonte: Dados da Pesquisa (2021).

Durante os seis anos analisados a maior parte dos casos notificados, resultaram em cura da doença. Provavelmente isso aconteceu por causa da utilização de diagnósticos e tratamentos adequado. Mesmo assim, ainda houve um número considerável de óbito pelo agravo da doença, registrando 16,35\% dos casos notificados (Tabela 4). A grande maioria dos casos de leptospirose são leveis e acabam regredindo naturalmente, e quanto antes se inicia o tratamento antibacteriano, menor é chance de desenvolverem o estágio mais grave da doença (HAAKE \& LEVETT, 2015).

Tabela 4: Distribuição de casos de leptospirose por evolução do caso no Estado do Ceará, entre 2014 a 2019.

\begin{tabular}{|c|c|c|c|c|c|c|c|c|}
\hline \multirow{2}{*}{ Variável } & \multicolumn{6}{|c|}{ Ano } & \multirow{2}{*}{ Total } & \multirow{2}{*}{$(\%)$} \\
\hline & 2014 & 2015 & 2016 & 2017 & 2018 & 2019 & & \\
\hline \multicolumn{9}{|l|}{ Evolução } \\
\hline Cura & 42 & 27 & 36 & 18 & 36 & 79 & 238 & $76,28 \%$ \\
\hline $\begin{array}{c}\text { Óbito pelo agravo } \\
\text { notificado }\end{array}$ & 6 & 2 & 11 & 4 & 11 & 17 & 51 & $16,35 \%$ \\
\hline Óbito por outra causa & 0 & 0 & 1 & 2 & 0 & 3 & 6 & $1,92 \%$ \\
\hline Ign/Branco & 2 & 0 & 1 & 4 & 4 & 4 & 17 & $5,45 \%$ \\
\hline
\end{tabular}

Fonte: Dados da Pesquisa (2021).

\section{CONCLUSÃO}

Diante dos dados analisados no presente estudo e em pesquisas anteriores, podemos considerar que a doença afeta principalmente a faixa etária economicamente ativa da população. A leptospirose é uma zoonose de grande importância para saúde pública, assim os resultados obtidos no presente estudo têm suma importância para a vigilância epidemiológica, além de servir como alicerce nas intensificações dos meios de prevenção, combate e controle da leptospirose no Ceará, com a finalidade de atenuar, a ocorrência desta doença e consequentemente diminuir as taxas dos indicadores epidemiológicos do estado. 


\section{DECLARAÇÃO DE INTERESSES}

Nós, autores deste estudo, declaramos que não possuímos conflitos de interesses de ordem financeira, comercial, político, acadêmico e pessoal.

\section{REFERÊNCIAS}

ADLER, B.; MOCTEZUMA, A. P. Leptospira and Leptospirosis. Veterinary Microbilogy, Amsterdam, v.140, n.3/4, p.287-296, 2010.

ANA. Agência Nacional de Águas. Uso múltiplos - Prevenção de inundações. 2000.

BARACHO, J. M.; LIMA, N. B.; COSTA, A. P. R. Incidência de casos de Leptospirose Humana em Pernambuco: uma análise dos dados epidemiológicos de 2015. Caderno de Graduação-Ciências Biológicas e da Saúde-FACIPE, v. 3, n. 2, p. 19, 2017.

BASSO, L. A.; RIGHI, E. Casos de hepatite e leptospirose no município de Porto Alegre-RS entre os anos de 2007 a 2011. Hygeia: Revista Brasileira de Geografia Medica e da Saúde, v. 11, n. 20, p. 66, 2015.

BRASIL, Ministério da Saúde. Departamento de Informática do SUS - DATASUS [inter-net]. Brasília: Ministério da Saúde; 2020.

BRASIL. Ministério da Saúde. Secretaria de Vigilância em Saúde. Departamento de Vigilância das Doenças Transmissíveis. Leptospirose: diagnóstico e manejo clínico / Ministério da Saúde, Secretaria de Vigilância em Saúde. Departamento de Vigilância das Doenças Transmissíveis. Brasília: Ministério da Saúde, p. 44, 2014.

BRASIL. Ministério da Saúde. Secretaria de Vigilância em Saúde. Leptospirose: Situação epidemiológica do Brasil no período de 2017 a 2016. V 49, $\mathrm{N}^{\circ}$ 41, 2018.

BRASIL. Ministério da Saúde. Secretaria de Vigilância em Saúde. Vigilância em saúde no Brasil 2003|2019: da criação da Secretaria de Vigilância em Saúde aos dias atuais. Bol Epidemiol. 2019.

BURR, P.; LUNN, K.; YAM, P. Current perspectives on canine leptospirosis. In Practice, v. 31, p. 98-102, 2009.

BUZZAR, M. R. Perfil epidemiológico da leptospirose no estado de São Paulo no período de 2007 a 2010. In: Anais da $1^{\text {a }}$ Conferência Internacional em Epidemiologia. 2011.

CEARÁ. Secretaria da Saúde. Leptospirose. Boletim Epidemiológico, Fortaleza, 2005.

CHAibliCH, J. V., LIMA, M. L. D. S., OLIVEIRA, R. F. D., MONKEN, M., \& PENNA, M. L. F. Estudo espacial de riscos à leptospirose no município do Rio de Janeiro (RJ). Saúde debate, Rio de Janeiro, v. 41, n. 2, p. 225-240, 2017.

CLAZER, M. Leptospirose e seu aspecto ocupacional - revisão de literatura. Arquivos de Ciências Veterinária e Zoologia-UNIPAR, Umuarama, v.18, n. 3, p. 191-198, 2015. 
FERNANDES, A. R. F.; FERNANDES, A. G.; ARAÚJO, V. J. A.; HIGINO, S. S. S.; SILVA, M. L. C. R.; ALVES, C. J.; AZEVEDO, S. S. Soroepidemiologia da leptospirose canina na região metropolitana de Natal, estado do Rio Grande do Norte. Rev.Braz. J. Vet. Res. Anim. Sci, Sao Paulo, v. 50, n. 3, p. 226-232, 2013.

FIGUEIRA, C. P. Caracterização de mutantes de Leptospira spp. na identificação de fatores de virulência. Tese (Doutorado em Patologia Humana) - Fundação Oswaldo Cruz, Centro de Pesquisas Gonçalo Moniz, Salvador, 2011.

FONSECA, Z. A. A. S.; BEZERRA, R. Q.; MOURA, E. S. R.; SOUSA, Ê. S.; OLIVEIRA, G. B. Roedores como um problema de saúde pública: experiência de programa de controle. Publicações em Medicina Veterinária e Zootecnia-PUBVET, Londrina, V. 5, N. 36, Ed. 183, 2011.

GREENE, C. E. Doenças infecciosas em cães e gatos. $4^{a}$ edição. São Paulo: Roca, 2015.

HAAKE, D. A.; LEVETT, P. N. Leptospirosis in humans. Current topics in microbiology and immunology, Berlin, Heidelberg, v.387, p. 65-97, 2015.

JORGE, R. S. P.; FERREIRA, F.; FERREIRA NETO, J. S.; VASCONCELLOS, S. D. A.; LIMA, E. D. S.; MORAIS, Z. M. D.; SOUZA, G. O. D. Exposição de livre-variando carnívoros selvagens, cavalos e cães domésticos para Leptospira spp. no norte do Pantanal, Brasil. Memórias do Instituto Oswaldo Cruz, v. 106, p. 441-444, 2011.

LARA, J. M.; VON ZUBEN, A.; COSTA, J. V.; DONALISIO, M. R.; FRANCISCO, P. M. S. B. Leptospiroses in Campinas, São Paulo, Brasil: 2007-2014. Revista Brasileira de Epidemiologia, v. 22, p. 2007-2014, 2019.

LEMOS, J. P.; MELO, C. B.; VIEGAS, S. A. R. A. Análise sorologica de Leptospira spp. em cães errantes no municipio de Aracaju. Revista Científica Eletrônica de Medicina Veterinária. n. 14, 2010 .

LEVETT, P. N. Leptospirosis: a forgotten zoonosis? Clinical and Applied Immunology Reviews, v. 4, n. 1, p. 435-448, 2004.

MARINHO, L. A. C.; TAVARES, W. Rotinas de Diagnóstico e Tratamento das Doenças Infecciosas e Parasitárias. 4a ed. São Paulo: Atheneu, 2015.

MARTIN, P. L.; STANCHI, N. O.; BRIHUEGA, B. F.; BONZO, E.; GALLI, L.; ARAUZ, M. S. Diagnóstico da leptospirose canina: avaliação de dois ensaios de PCR em comparação com o teste de microaglutinação. Pesq. Veterinario. Bras. Rio de Ja-neiro, v. 39, n. 4, p. 255-262, 2019.

OliveirA, H. H.; RODRIGUES, M. A. M.; SANTOS, I. S.; FRANCISCHETTI, C. N. Perfil epidemiológico e socioeconômico da ocorrência de casos de leptospirose em municípios da Baixada Fluminense, Rio de Janeiro, Brasil. Enciclopédia Biosfera, v. 13, n. 23, p. 1479-91, 2016. 
PARREIRA, I. M. Aspectos epidemiológicos da infecção por leptospira spp. Em felinos domésticos (felis catus) aparentemente sadios da região metropolitana de Goiâ-nia, Goiás. 2009. 70 f. Dissertação (Mestrado em Ciências Agrárias - Veterinária) - Universi-dade Federal de Goiás, Goiânia, 2009.

PEREIRA, B. F.; BASSANI, D. C. H.; CHAVES, J.; TABILE, P. M.; KRUMMENAUER, E. C.; CARNEIRO, M. Perfil Clínico da Leptospirose em Santa Cruz do Sul (RS): Revisão Dos Anos De 2012 e 2013. Blucher Medical Proceedings, v. 1, n. 5, p. 39-39, 2014.

RODRIGUES, A. M. A. Leptospirose canina: diagnóstico etiológico, sorológico e molecular e avaliação da proteção cruzada entre os sorovares icterohaemorrhagiae e copenhageni. Tese de Mestrado, Universidade de São Paulo, São Paulo, 2008.

RODRIGUES, A. L. Perfil epidemiológico de pacientes acometidos por leptospirose em um estado brasileiro na Amazônia Ocidental. Revista Sustinere, v. 7, n. 1, p. 32-45, 2019.

SALOMÃO, R. Infectologia: Bases clínicas e tratamento. $1^{a}$ edição. Rio de Janeiro: Guanabara Koogan. 2017

SAMPAIO, G. P.; WANDERLEY, M. R.; CASSEB, G. B.; NEGREIROS, M. A. M. P. Descrição epidemiológica dos casos de leptospirose em hospital terciário de Rio Branco. Revista Brasileira Clínica Médica, v. 9, n. 5, p. 338-343, 2011.

SOUZA, V. R. Leptospirose: aspectos epidemiológicos, clínicos e laboratoriais. Trabalho de conclusão de curso (Pós-graduação em Análises Clínicas e Gestão de Laboratório) - Universidade Vale do Rio Doce, Minas Gerais, 2011.

TEIXEIRA, M. A.; GONÇALVES, M. L. L.; RIEDIGER, I. N.; PROSSER, C. S; SILVA, S. F. C.; BIESDORF, S. M.; MOSKO, P. R. E.; MORAIS, H. A.; BIONDO, A. W. Sorologia negativa e PCR positiva: a importância da biologia molecular para o diagnóstico de leptospirose aguda em um cão. Clínica Veterinária, São Paulo, v.8, n.73, p. 44-48. 2008. 


\section{Índice remissivo}

A

A. Albopictus 76,77

Acidentes com aranhas 148, 150, 155

Acidentes com escorpiões 40, 41, 42, 43, 45, 47, 48, 175

Aedes 61, 62, 65, 66, 76, 77, 79, 80, 138, 139, 141, 144

Aedes aegypti 61, 62, 65, 66, 77, 79, 80, 138, 139, 144

Agentes infecciosos 117, 118

Alphavirus 76, 77

Animais domésticos 96, 181, 183

Animais peçonhentos 41, 42, 47, 148, 149, 150, 156, 157, 158, 168, 169, 170, 171, 172, 173, 174, $175,176,177,178,179$

Animais selvagens 181

Animais venenosos 148

Antropozoonose 127, 128

Aracnidismo/epidemiologia 148

Aranhas 148, 149, 150, 151, 152, 153, 155, 156, 157, 158, 169, 171

Arbovirose 61, 62, 64, 76, 79, 140, 141, 143

Artrópodes 138

B

Bacilo de koch 51, 52

Bactéria gram-positiva 30,31

C

Calazar $68,69,200$

Chikungunya $76,77,80,81,146$

Cisticercose 19, 20, 21, 22, 23, 24, 25, 26, 27, 28

Cisticercose humana 19, 20, 25, 26, 27

Clostridium tetani 30, 31

Comitê de ética 22, 40, 42, 63, 78, 97, 148, 151, 162, 184, 194, 204, 215

Complexo teníase-cisticercose 19, 20, 21, 27, 28

Comunidades da periferia 51,57

Condições ambientais 61

Controle 36, 40, 46, 47, 53, 58, 61, 65, 73, 77, 95, 102, 104, 109, 129, 141, 143, 155, 160, 165, 176, 178, 181, 183, 184, 185, 187, 189, 194, 199, 209, 213, 218, 219

$\mathrm{D}$

Defeitos imunológicos 83, 84

Dengue 61, 62, 63, 64, 65, 66, 144, 145

Denv-1 61,62

Denv-2 61, 62

Denv-3 61, 62

Denv-4 61, 62 
Desigualdades sociais 51,57

Diagnóstico precoce 51, 57,89, 166

Doença de chagas 103, 127, 128, 129, 130, 131, 132, 133, 134, 135, 136

Doença de chagas (dc) 95, 97

Doença infectocontagiosa 51, 52

Doença infecto-parasitária 213, 214

Doença negligenciada 192, 199

Doenças infecciosas emergentes 61,62

Doenças parasitarias 19, 127

Doenças sexualmente transmissíveis 202

$\mathrm{E}$

Enfermidade parasitária 213

Envenenamento 40, 47, 150, 151, 155

Enzootia de animais silvestres 127

Epidemiologia 19, 30, 38, 46, 47, 48, 51, 58, 59, 73, 76, 80, 81, 92, 95, 103, 104, 123, 124, 127, $134,135,144,145,158,160,168,177,178,188,189,192,202,219$

Escorpião 168, 171

Escorpionismo 40, 41, 42, 46, 48

Esquistossomose 213, 214, 215, 216, 217, 218, 219

$\mathrm{F}$

Falta de assistência primária 51

Febre de chikungunya 76

Flavivirus 62, 138, 139

Flebotomíneos $68,69,71,72,74,98$

$\mathrm{H}$

Hepatite 92, 202, 204, 207, 210, 211

Hepatite b 202, 203, 204, 205, 206, 208, 209, 210, 211

Higiene corporal e da moradia 19, 25

Hospedeiro definitivo 19, 20

Hospedeiro intermediário 19, 20, 213, 218

I

Impacto epidemiológico da covid-19 107, 109

Infecção de animais 19, 25

Infecções por arbovírus 76

Inflamação nas meninges 117,118

Intoxicação humana 148, 149

$\mathrm{L}$

Leishmania 68, 69, 192, 193, 194

Leishmaniose tegumentar americana (lta) 95, 97

Leishmaniose visceral (lv) 68, 70

Leptospira 181, 182, 183, 188, 189 
Leptospirose 181, 182, 183, 184, 188, 190

$\mathrm{M}$

Macrófagos 68, 69

Malária 95, 96, 97, 98, 99, 100, 102, 103, 160, 161, 162, 163, 164, 165, 166

Meningites 117, 118, 122, 123, 124

Meningites infecciosas 117, 118

Meningite viral 117,118

Microrganismos 181

Monócitos 68, 69

Mycobacterium tuberculosis 51, 52

$\mathrm{O}$

Organização mundial da saúde 30, 37, 69, 108, 140, 194

$\mathrm{P}$

Pandemia da covid-19 107, 109, 112

Picada de escorpião 40, 42

Plasmodium 160, 161, 162, 164, 165, 166

Portadores de teníase 19, 21, 24

Prevenção 30, 33, 37, 38, 40, 45, 46, 85, 87, 90, 92, 96, 101, 104, 112, 122, 123, 129, 133, 148, $156,160,165,166,170,176,181,183,187,199,204,209,211,213,218$

Profissionais de saúde 107

Programas de acompanhamento 51, 57

Programas socioambientais 213, 215

Protozoários parasitos 68, 69

$\mathrm{S}$

Saneamento básico 19, 21, 23, 24, 25, 96, 119, 143, 186, 214, 218

Saúde pública 19, 20, 21, 24, 27, 37, 40, 41, 46, 58, 61, 65, 85, 91, 96, 108, 114, 117, 119, 139, $149,155,161,169,181,183,187,189,194,202,203,204$

Serpente 168,171

Shistosoma mansoni 213,214

Síndrome da imunodeficiência adquirida (aids) 83, 84, 85, 86, 88, 90

Sistema de informação de agravos de notificação $30,32,42,51,53,70,76,78,85,86,117,118$, $119,127,129,150,160,161,162,181,204,213,214,215$

Sistema único de saúde 21, 30, 32, 42, 78, 89, 95, 97, 127, 129, 145, 150, 204

Sorotipos virais 61,62

$\mathrm{T}$

Taenia solium 19, 20, 26, 27

Tétano 30, 31, 37, 38

Tétano acidental (ta) 30, 31

Tratamento $24,37,51,57,65,87,91,120,122,142,143,156,161,162,176,183,186,187,190$, 209

Trematódeos 213, 214 
Tripanosoma cruzi 127,128

Tuberculose 51, 52, 53, 54, 55, 56, 57, 58, 59

$\mathrm{U}$

Urina de animais 181

$\mathrm{V}$

Vigilância epidemiológica 40, 178

Vírus da imunodeficiência humana (hiv) $83,84,86,89$

Víus 76

Z

Zika vírus 138, 139

Zona de residência 30, 32, 51, 53, 56, 57, 70, 72, 73, 95, 97, 100, 101, 127, 129, 132, 181, 183, 186, 192, 194, 202, 204, 209

Zona rural 27, 56, 72, 95, 100, 101, 102, 127, 132, 133, 192, 198, 199

Zoonoses 95, 96, 97, 98, 99, 100, 102

Zoonoses parasitárias 95 


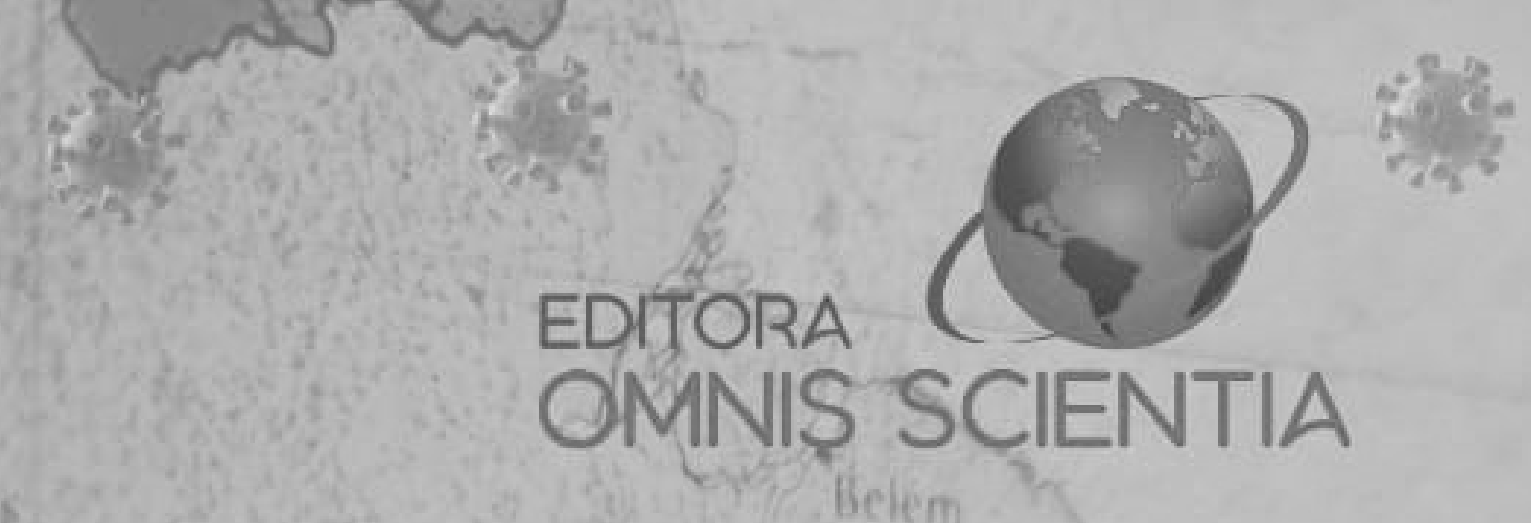

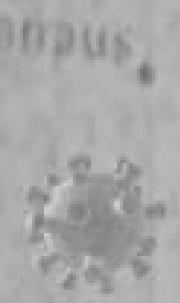
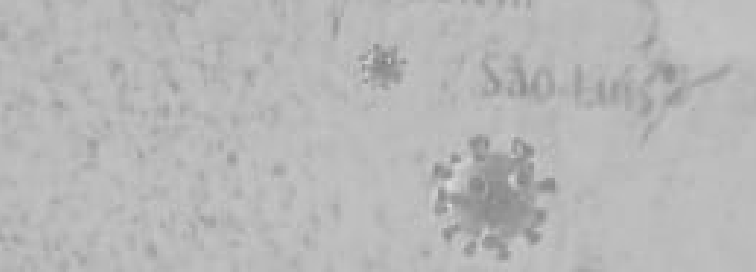

परे

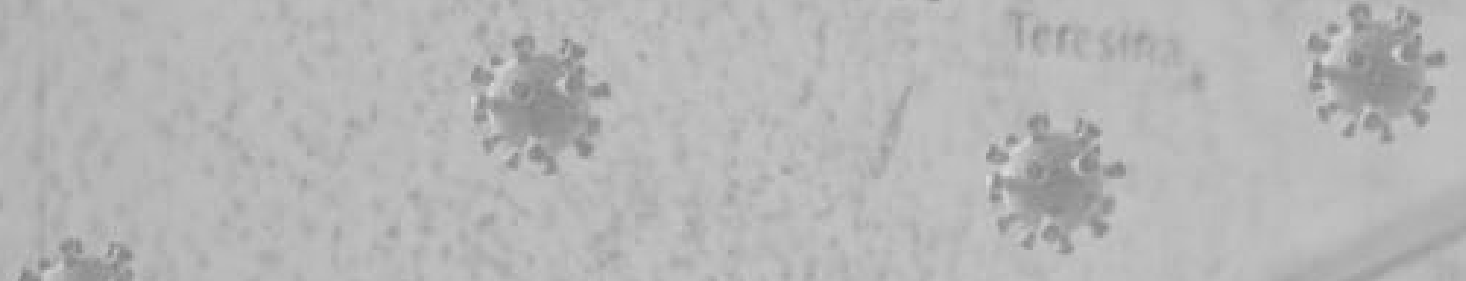

$\log _{3}^{2}$

$\frac{k^{2}}{x^{2}}$

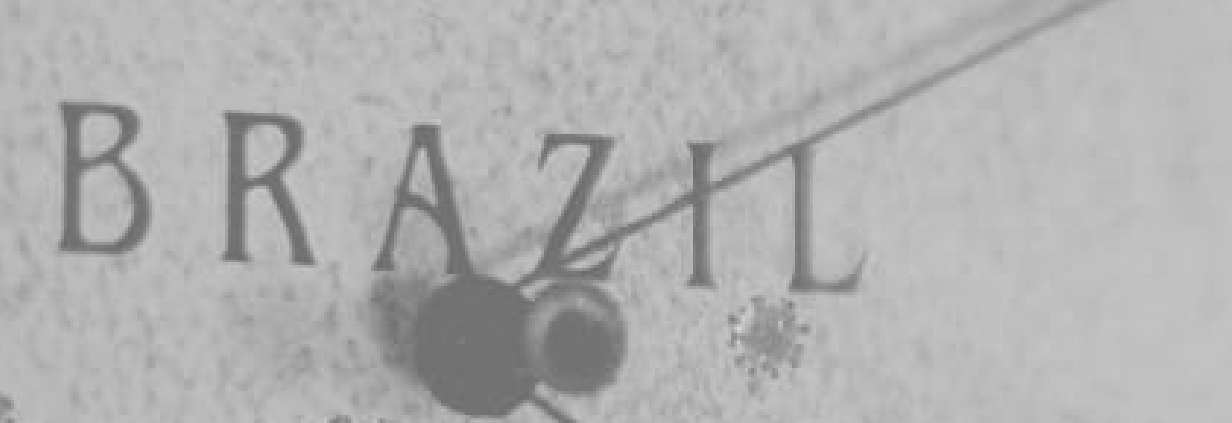

की है:

\section{है:

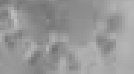

tis.

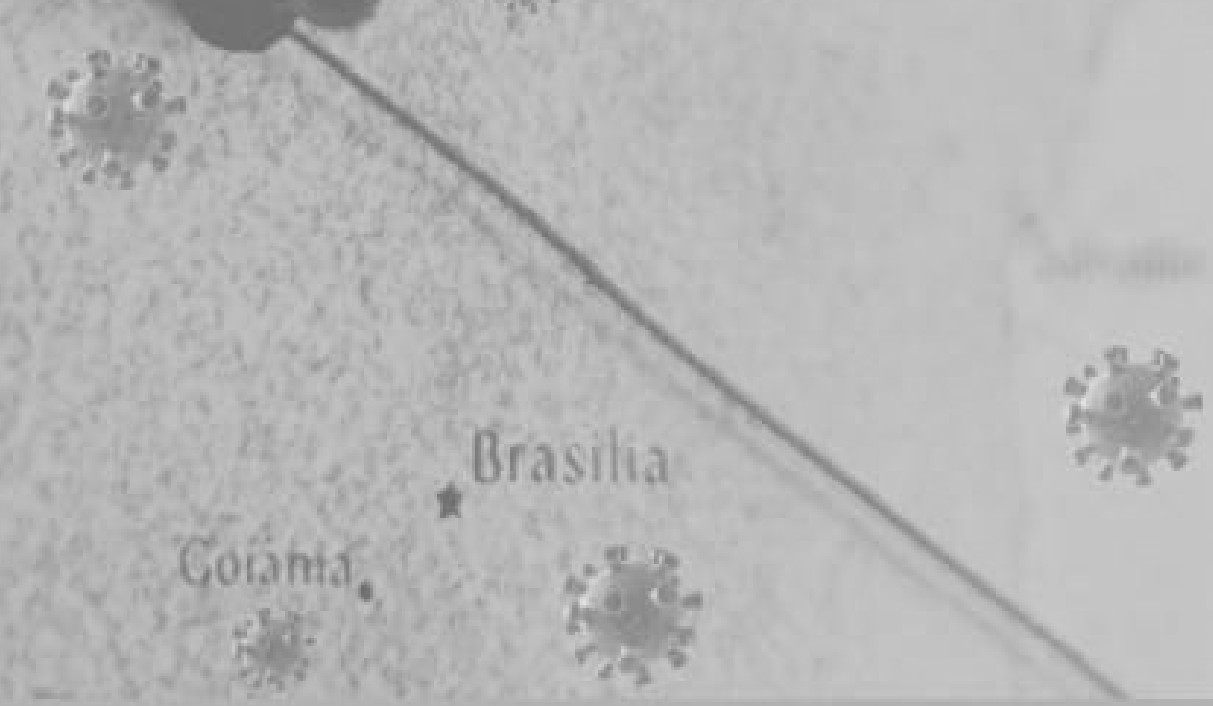

editoraomnisscientia@gmail.com M https://editoraomnisscientia.com.br/ 9

@editora_omnis_scientia (0)

https://www.facebook.com/omnis.scientia.9 f

+55 (87) 9656-3565 (2)

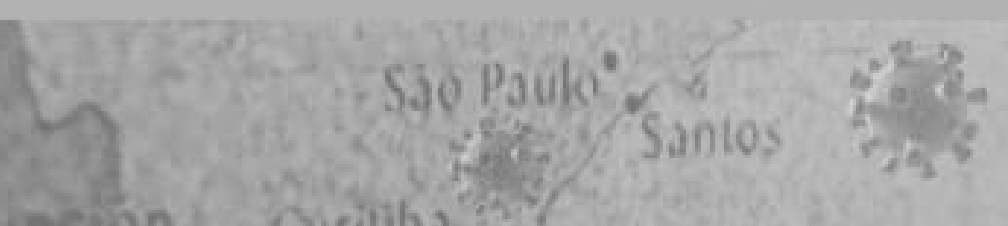


